\title{
EFFECT OF THE LOAD CHARACTER AND CRYOGENIC TEMPERATURE ON ELASTIC PROPERTIES OF TI-6AL-4V TITANIUM ALLOY
}

\author{
R. Soltysiak*
}

\begin{abstract}
The main parameter describing elastic properties of materials is the modulus of elasticity. The modulus of elasticity is used not only to determine the value of the elastic strain, but in consequence also to determine the value of the total strain in the range of plastic strain. Therefore, the selection of the appropriate modulus for specific operating conditions is of decisive importance here. The paper presents a comparative analysis of the Young's modulus with cyclic moduli determined for the rising and falling loop, for the straight line connecting the edges of the hysteresis loop and the average moduli. The tests were carried out for Ti-6Al-4V titanium alloy at room temperature and cryogenic temperature. The conducted tests have shown that the values of cyclic moduli change during cyclic loads. The values of the cyclic moduli for the rising loop are larger than the Young's modulus.
\end{abstract}

Keywords: Ti-6AI-4V, cyclic modulus, cryogenic, elastic properties, cyclic properties

\section{Introduction}

One of the basic material properties used in strength, stiffness and durability analyzes is the tensile elasticity modulus (Ligaj and Szala, 2012; Lipski, 2016). The modulus of elasticity is used in various simulations of machines/equipment or their components exposed to static loads (Cichanski, 2016) as well as loads variable over time (Stopel et al., 2017; Tomaszewski et al., 2016). Appropriate determination of its value is of key importance here.

The modulus of elasticity during a monotonic tensile test is determined on the basis of the curve obtained during the test. There are at least three types of moduli: Young's Modulus, Tangent Modulus, and Chord Modulus (ASTM E111, 2017). In the case of tests performed with loads varying over time, the moduli, which are generally called "cyclic" ones for the purpose of this paper, are determined based on the obtained hysteresis loop diagrams.

There is, among others, a cyclic modulus specified for the branches of the rising loop and for the branches of the falling loop. In the paper (Maletta et al., 2014) it was demonstrated that for Ni-Ti alloy, for research performed at room temperature, the cyclic modulus decreases with the first load cycles and then it stabilizes after the 20th load cycle. While in the paper (Bönisch et al., 2015) the Ti-Nb alloy was tested at cyclic loading-unloading experiments in compression. There is also one more cyclic modulus presented there determined as the slope of a straight line connecting the loop corners. The value of this modulus was between the values of modulus determined from the rising and the falling branches. However, for this material, cyclic moduli determined for rising and falling hysteresis loops differed even by up to $35 \%$.

In view of the above, doubts arise as to which kind of modulus to use for describing, for example, cyclic material properties in the form of a cyclic stress-stain curve (CSS) described by the Ramberg-Osgood equation (R-O) (Ramberg and Osgood, 1943). The existing recommendations (B. Thomas et al., 1989) indicate that the Young's modulus E can be estimated by cycling within the elastic limit of the first quarter of the hysteresis loop at the test temperature for each test. The modulus for describing cyclic

Robert Sołtysiak, PhD.: UTP University of Sciences and Technology in Bydgoszcz, Faculty of Mechanical Engineering, al. Prof. S. Kaliskiego 7; 85-796, Bydgoszcz, PL, robert.soltysiak@utp.edu.pl 
properties can also be determined as an average value from the value of cyclic moduli determined from the rising and falling branches of the hysteresis loop (Hales et al., 1993).

This paper presents a comparative analysis of the moduli determined on the basis of the standard monotonic tensile test $(E)$ with cyclic moduli determined for the rising $\left(E_{R}\right)$ and falling $\left(E_{U}\right)$ loop, for the straight line connecting the edges of the hysteresis loop $\left(\mathrm{E}_{\mathrm{S}}\right)$ and the average moduli $\left(\mathrm{E}_{\mathrm{A}}\right)$. The tests were carried out for Ti-6Al-4V titanium alloy at room temperature (RT) and cryogenic temperature (CT). The studies presented below indicate that the results for cyclic moduli differ from those for the modulus obtained from the monotonic tensile test. The paper also presents a change in the value of cyclic moduli as a function of the growing number.

\section{Research object and method}

The material tested in this study is Ti-6Al-4V titanium alloy. Chemical composition of this alloy and properties obtained from the static tensile test are presented in Tab. 1. The fatigue tests were carried out for samples taken from a $10 \mathrm{~mm}$ thick sheet metal plate (Fig.1) at RT and at CT. Tests in liquid nitrogen were carried out using a local compartment. Photographs taken during tests are presented in Fig. 2.

Tab. 1: Chemical composition and mechanical properties of Ti6A14V titanium alloy (Boroński et al., 2017).

\begin{tabular}{|c|c|c|c|c|c|c|c|c|}
\hline \multicolumn{4}{|c|}{ Chemical Composition (\%) } & \multicolumn{5}{|c|}{ Tensile properties } \\
\hline $\mathbf{O}$ & $\mathbf{V}$ & Al & $\mathbf{F e}$ & Test temp. & $S_{u}\left(R_{m}\right)$ & $S_{y}\left(R_{p 0.2}\right)$ & $\mathbf{E}$ & $\mathbf{A}_{5}$ \\
\hline$<0.20$ & 3.50 & 5.50 & $<0.30$ & $\mathrm{~K}$ & $\mathrm{MPa}$ & $\mathrm{MPa}$ & $\mathrm{GPa}$ & $\%$ \\
\hline $\mathbf{H}$ & $\mathbf{C}$ & $\mathbf{N}$ & $\mathbf{T i}$ & $293(\mathrm{RT})$ & 908 & 859 & 111.7 & 13.6 \\
\hline$<0.0015$ & $<0.08$ & $<0.05$ & balance & 77 (CT) & 1392 & 1344 & 128.6 & 12.1 \\
\hline
\end{tabular}

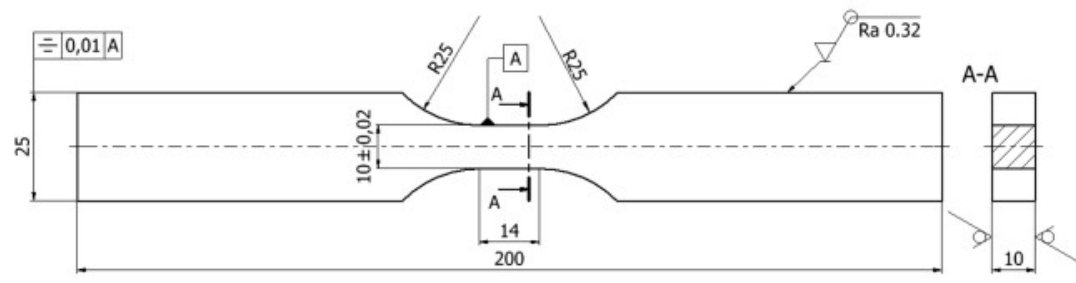

Fig. 1: Low-cycle test sample

a)

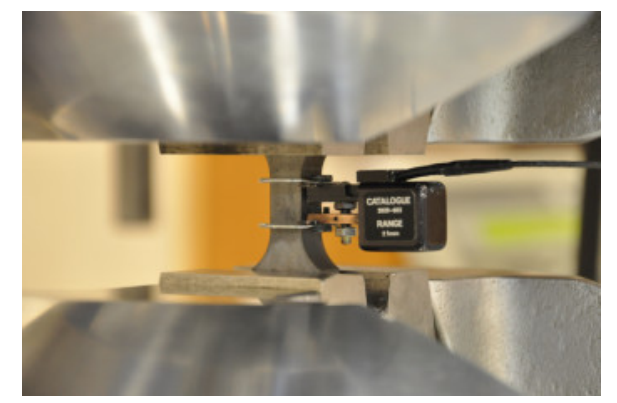

b)

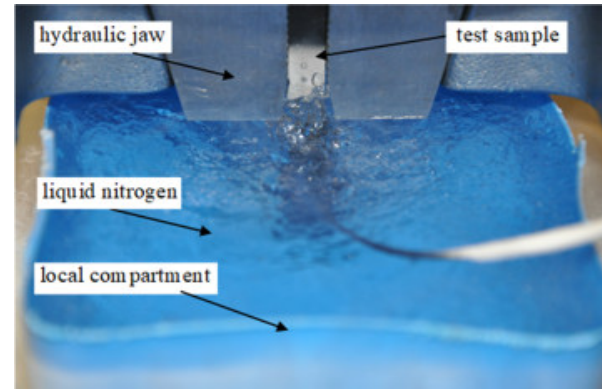

Fig. 2: View of the test measuring at $R T$ (a) and at CT with the measuring part of the sample immersed in liquid nitrogen (b)

Low-cycle tests were performed using the INSTRON 8502 testing machine while controlling the strain value. The tests were carried out using an extensometer with a $10 \mathrm{~mm}$ measuring base and a measuring range of $+/-1$ $\mathrm{mm}$. The tests were carried out at a frequency of $0.2 \mathrm{~Hz}$ and a cycle asymmetry ratio of $\mathrm{R}=-1$. The loading program was divided into three steps: I, III - gradually increasing steps and II - gradually decreasing step. The sample loading scheme is shown in Fig. 3a. The $\mathrm{E}_{\mathrm{R}}, \mathrm{E}_{\mathrm{U}}$ and $\mathrm{E}_{\mathrm{S}}$ cyclic moduli were determined in accordance with the diagram shown in Figure $3 b$. The average cyclic modulus is defined as $E_{A}=\left(E_{R}+E_{U}\right) / 2$.

\section{Results and Discussions}

The diagrams of the determined cyclic moduli $\left(\mathrm{E}_{\mathrm{R}}, \mathrm{E}_{\mathrm{U}}, \mathrm{E}_{\mathrm{S}}\right)$ as a function of the number of cycles and against the background of the control (total) strain $\varepsilon$ value and the modulus $E$ are shown in Fig. 4. At the 
beginning of the test, the values of the cyclic moduli and the values of the E moduli are virtually the same. Then the values of the cyclic moduli begin to change along with the increase in the control strain and the number of cycles. Initially, the value of most of them $\left(E_{R, R T}, E_{R, C T}, E_{U, C T}, E_{S, C T}\right)$ increases, then a period of slight changes appears, and after exceeding a certain $\varepsilon$ value, the values of cyclic moduli begin to decrease. The drop in the value of $\mathrm{E}_{\mathrm{R}, \mathrm{RT}}$ and $\mathrm{E}_{\mathrm{U}, \mathrm{RT}}$ moduli takes place in the range of $\varepsilon$ values from 0.68 to $0.87 \%$. While for tests at CT, for a value of $\varepsilon$ equal to approximately $0.9 \%$.

a)

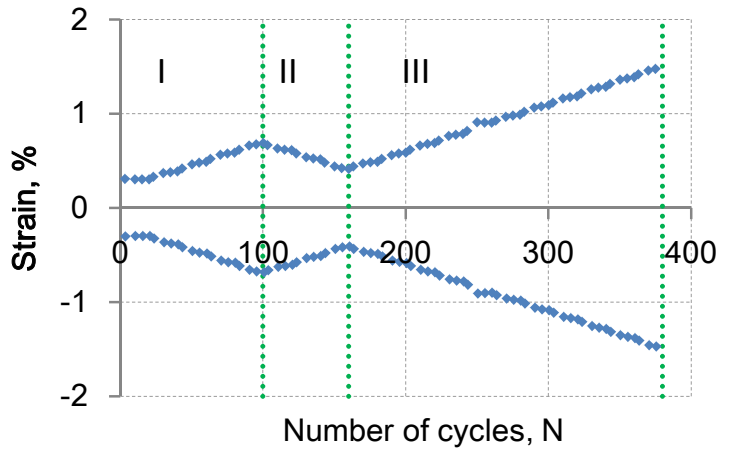

b)

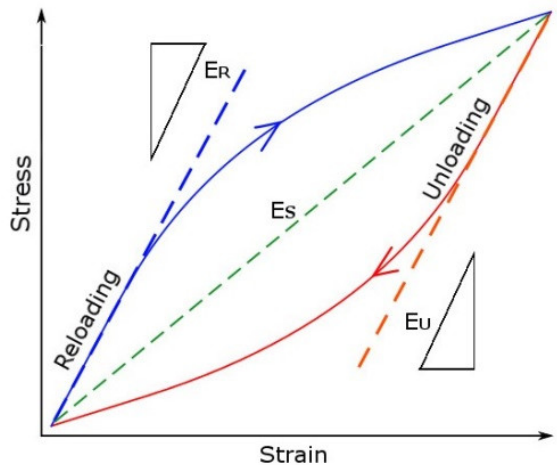

Fig. 3: Load implementation program - a) and the scheme for determining the cyclic moduli - b)

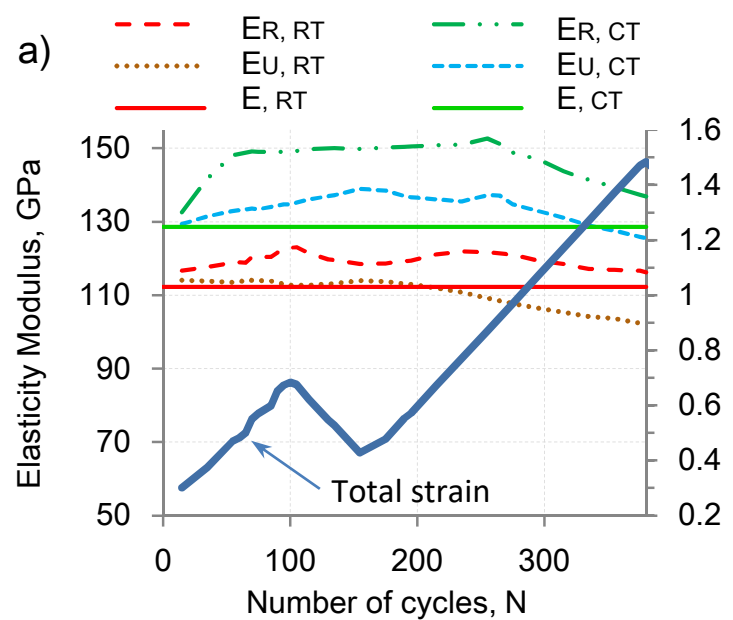

b) $\cdots E S, R T \quad \cdots E S, C T$

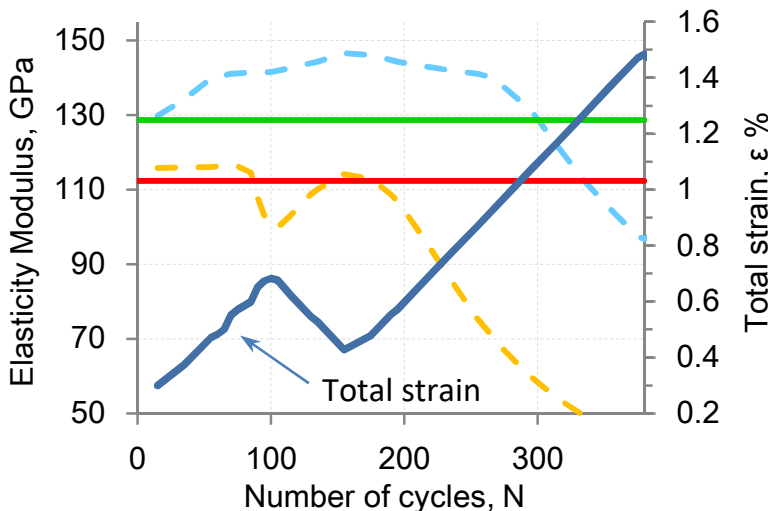

Fig. 4: Comparative analysis of changes in the $E_{R}, E_{U}(a)$ and $E_{S}(b)$ values as a function of the increasing number of cycles

A distinct decrease in the value of the cyclic secant $\left(\mathrm{E}_{\mathrm{S}}\right)$ modulus is observable for tests at $\mathrm{CT}$. The value of strain $\varepsilon$ at which a significant decrease in the value of the cyclic $\mathrm{E}_{\mathrm{S}}$ modulus coincides with the value of strain where the value of $E_{R}$ and $E_{U}$ cyclic moduli decreases. While at RT the first significant decrease in the value of $E_{S}$ is observed after the 80th cycle and it corresponds to the value of the control strain $\varepsilon$ of about $0.7 \%$.

Drops in cyclic moduli, in particular the $\mathrm{E}_{\mathrm{S}}$ modulus, are associated with the appearance of significant plastic strain. The appearance of significant plastic strain and accompanying dislocations results in decrease in the stiffness of the tested sample in the form of a decrease in the value of the tested moduli. Noticeable decline in the value of cyclical moduli appeared earlier (both as regards the value of $\varepsilon$ as well as the amount of load cycles made) at RT than at CT. It has generally been proven that the cryogenic temperature improves and stabilizes the structure of the crystal lattice of alloy metals (Xu et al., 2016) which may also cause increase in the value of the moduli at CT compared to RT.

Table 2 also includes the average modulus $\mathrm{E}_{\mathrm{A}}$ used, as recommended (Hales et al., 1993), in order to describe CSS. The table also includes statistical analyzes of the results obtained and the difference in the arithmetic mean of the cyclic moduli was compared to the E modulus. The values of cyclic moduli at CT are higher than the modulus $\mathrm{E}$. The cyclic modulus $\mathrm{E}_{\mathrm{R}}$ is higher even by up to $14 \%$ from the modulus $\mathrm{E}$. Smaller differences are observed for the values of $E_{R}$ and $E_{U}$ cyclic moduli obtained at RT. The largest difference concerns the $\mathrm{E}_{\mathrm{S}}$ modulus at RT. In this case, a large standard deviation of 26.5 was recorded. 
This is due to the fact that the value of the $\mathrm{E}_{\mathrm{S}}$ modulus was constantly decreasing starting from around the half of the tested range.

Tab. 2: The average value and standard deviation of the determined moduli.

\begin{tabular}{|c|c|c|c|c|c|c|c|c|}
\hline \multirow{2}{*}{$\begin{array}{c}\text { Modulus } \\
\text { Test temp. }\end{array}$} & \multicolumn{2}{|c|}{$\mathbf{E}_{\mathbf{R}}, \mathbf{G P a}$} & \multicolumn{2}{|c|}{$\mathbf{E}_{\mathbf{U}}, \mathbf{G P a}$} & \multicolumn{2}{|c|}{$\mathbf{E}_{\mathbf{S}}, \mathbf{G P a}$} & \multicolumn{2}{|c|}{$\mathbf{E}_{\mathrm{A}}, \mathbf{G P a}$} \\
\hline & RT & $\mathrm{CT}$ & RT & CT & RT & $\mathrm{CT}$ & RT & $\mathrm{CT}$ \\
\hline Arithmetic average & 119.6 & 146.6 & 111.0 & 133.7 & 93.8 & 133.6 & 115.3 & 140.1 \\
\hline Standard deviation & 1.9 & 5.5 & 4.0 & 3.9 & 26.5 & 15.3 & - & - \\
\hline Difference * & 7.1 & 14.0 & -0.6 & 4.0 & -16.0 & 3.9 & 3.2 & 9.0 \\
\hline
\end{tabular}

\section{Conclusions}

The paper presents a comparison of Young's moduli E determined at RT and CT with the following cyclic moduli: $\mathrm{E}_{\mathrm{R}}$ - determined from the reloading loop, $\mathrm{E}_{\mathrm{U}}$ - determined from the unloading loop, $\mathrm{E}_{\mathrm{S}}$ - determined from the slope of a straight line connecting the loop corners and $\mathrm{E}_{\mathrm{A}}$ - determined as the average value from $\mathrm{E}_{\mathrm{R}}$ and $\mathrm{E}_{\mathrm{U}}$. The conducted tests have shown that the values of cyclic moduli change during cyclic loads. The changes are related to the load history as well as the value of the control variable. The value of cyclic moduli $\mathrm{E}_{\mathrm{R}}$ is higher compared to the $\mathrm{E}$ modulus. The same applies to the values of $\mathrm{E}_{\mathrm{A}}$ moduli. According to the recommendations, (Hales et al., 1993) when describing the cyclic properties of Ti-6Al-4V titanium alloy, the value of $\mathrm{E}_{\mathrm{A}}=115.3 \mathrm{GPa}$ for $\mathrm{RT}$ and $\mathrm{E}_{\mathrm{A}}=140.1 \mathrm{GPa}$ for $\mathrm{CT}$ should be assumed.

\section{Acknowledgment}

The results of the experimental research were obtained in the framework of the Research Project No. PBS2/A5/35/2013 funded by the National Center for Research and Development.

\section{References}

ASTM E111 (2017). Standard Test Method for Young's Modulus, Tangent Modulus, and Chord Modulus.

Thomas, G. B., Hales, R., Ramsdale, J., W. Suhr, R., and Sumner, G. (1989). A code of practice for constantamplitude low cycle fatigue testing at elevated temperature. Fatigue \& Fracture of Engineering Materials \& Structures 12, 135-153.

Bönisch, M., Calin, M., van Humbeeck, J., Skrotzki, W., and Eckert, J. (2015). Factors influencing the elastic moduli, reversible strains and hysteresis loops in martensitic Ti-Nb alloys. Materials Science and Engineering: C 48, 511-520.

Boroński, D., Kotyk, M., Maćkowiak, P., and Śnieżek, L. (2017). Mechanical properties of explosively welded AA2519AA1050-Ti6A14V layered material at ambient and cryogenic conditions. Materials \& Design 133, 390-403.

Cichanski, A. (2016). The Influence of Mesh Morphology on the Scf in 2d Fem Analysis of Flat Bars with Opposite V-Notch Under Tension. In: Engineering Mechanics 2016, IT AS CR, Prague, pp. 110-113.

Hales, R., Holdsworth, S.R., O’Donnel, M.P., Perrin, I.J., and Skelton, R.P. (1993). A Code of Practice for the determination of cyclic stress-strain data. Materials at high temperatures 19 (4), 165-185.

Ligaj, B., and Szala, G. (2012). Comparative analysis of fatigue life calculation methods of C45 steel in conditions of variable amplitude loads in the low- and high-cycle fatigue ranges. Pol. Marit. Res. 19, $23-30$.

Lipski, A. (2016). Accelerated determination of the fatigue limit and the S-N curve by means of the thermographic method for X5CRNI18-10 steel. Acta Mech. Automatica 10, 22-27.

Maletta, C., Sgambitterra, E., Furgiuele, F., Casati, R., and Tuissi, A. (2014). Fatigue properties of a pseudoelastic NiTi alloy: Strain ratcheting and hysteresis under cyclic tensile loading. International Journal of Fatigue 66, 78-85.

Ramberg, W., and Osgood, W.R. (1943). Description of stress-strain curves by three parameters. Technical Note National Advisory Committee for Aeronautics.

Stopel, M., Skibicki, D., and Moćko, W. (2017). Method for determining the strain rate sensitivity factor for the Johnson-Cook model in Charpy tests. MP 59, 965-973.

Tomaszewski, T., Strzelecki, P., and Sempruch, J. (2016). Geometric Size Effect in Relation to the Fatigue Life of S355j2 $+\mathrm{c}$ Steel Under Variable Bending Conditions. In: Engineering Mechanics 2016, IT AS CR, Prague, pp. 554-557.

Xu, L.Y., Zhu, J., Jing, H.Y., Zhao, L., Lv, X.Q., and Han, Y.D. (2016). Effects of deep cryogenic treatment on the residual stress and mechanical properties of electron-beam-welded Ti-6Al-4V joints. Materials Science and Engineering: A 673, 503-510. 